\title{
Robotic Removal of a Hypogastric Splenic Cyst. A Case Report and Review of Literature
}

\author{
Petros Hirides $^{1 *}$, Savas Hirides ${ }^{1}$, Aggelos Margeths ${ }^{2}$, Pericles Chrysoheris1, \\ Fotios Antonakopoulos' ${ }^{1}$, Konstantinos M. Konstantinidis ${ }^{1}$ \\ ${ }^{1}$ Department of General, Laparoscopic, Robotic \& Bariatric Surgery, Athens Medical Center, Marousi, Greece \\ ${ }^{2}$ Kapodistrian University of Athens, School of Medicine, Athens, Greece \\ Email: ${ }^{*}$ dr.hiridis@gmail.com
}

Received 7 May 2014; revised 1 June 2014; accepted 9 June 2014

Copyright (C) 2014 by authors and Scientific Research Publishing Inc.

This work is licensed under the Creative Commons Attribution International License (CC BY). http://creativecommons.org/licenses/by/4.0/

(c) () Open Access

\section{Abstract}

Background: Splenic cysts are infrequent findings in everyday medical practice. They are usually associated with nonspecific symptoms and the diagnosis is incidental. In most instances they are located in the left subcostal region, except for cases of huge sized cysts which can extend to the whole abdomen or pelvis. Aim: To present a case of a large hypogastric splenic cyst in a nulliparous woman, managed with robotic cystectomy. Review of the literature is included. Case: A 19year-old woman, presented to the gynecologic department with a painless, palpable mass in the lower abdomen. Ultrasonography revealed a pelvic cystic mass, originally misdiagnosed for an ovarian cyst. Serum biomarkers and $\beta$-hCG were negative. Definite diagnosis was made during explorative laparoscopy where the cyst was found to originate from the spleen. The surgery setup was changed from a lower to upper abdominal procedure. A robotically-assisted cystectomy was performed without concurrent splenectomy, and the splenic cavity was filled with an omental patch. There was no blood loss and the operation time was 163 minutes. Recovery was uneventful and there was no recurrence for a period of 16 months postoperatively. Conclusions: Pelvic splenic cysts are rare, and may be incidental findings during routine abdominal ultrasound scans. Modern minimally invasive approaches such as robotic surgery offer safe and efficient alternatives to standard techniques.

\section{Keywords}

\section{Splenic Cyst, Hypogastric Cyst, Ovarian Cyst, Robotic Surgery, Cystectomy}

\footnotetext{
*Corresponding author.
}

How to cite this paper: Hirides, P., Hirides, S., Margeths, A., Chrysoheris, P., Antonakopoulos, F. and Konstantinidis, K.M. (2014) Robotic Removal of a Hypogastric Splenic Cyst. A Case Report and Review of Literature. Surgical Science, 5, $264-271$. 


\section{Introduction}

Splenic cysts are considered to be uncommon during routine surgical practice. Martin et al. have classified splenic cysts as either primary (true) or secondary (false) [1]. Type I (or primary) cysts are characterized by the presence of cellular capsule and are mainly found in children and young adults. They are further divided into parasitic and non-parasitic cysts. Splenic cysts of parasitic origin occur mostly after infection by Tenia Echinococcus and have an increasing prevalence in Africa and Central America [2]. Non-parasitic cysts can be congenital, vascular or neoplastic while the congenital ones are categorized into epidermoid, dermoid and endodermoid cysts. Type II (or secondary) cysts have no epithelial capsule and are mainly caused by traumatic, degenerative and inflammatory processes. They are also called pseudocysts and their incidence is four times more than true cysts.

Thirty to 60 percents of splenic cysts are asymptomatic until they reach a significant diameter (usually $>8 \mathrm{~cm}$ ) [3]. Atypical symptoms include a painless mass and heaviness in the left epigastrium, splenomegaly, nausea, vomiting, diarrhea, weight loss and radiating left-shoulder pain [4] [5]. Moreover, effects on the cardiorespiratory system may lead to pleuritic pain, dyspnea and persistent cough [6]. Life-threating complications such as infection and hemorrhage have been rarely reported [7]. The identification of a palpable mass in the left upper abdominal quadrant requires thorough examinations. Ultrasonography is the main tool for diagnosis, where the cysts appear to be anechoic or hypoechoic with well-defined smooth thin walls. Calcifications and other abnormalities of cyst walls may be observed. Important anatomical and morphological information is also provided by computer tomography and magnetic resonance [4] [8] [9]. Angiography can differentiate a splenic cyst from solid malignant tumors which would be usually present with neoplastic, disorganized vasculature [10]. Although hematological, biochemical, and serological considerations are negative in most patients, they are frequently significant in excluding diseases associated to splenomegaly, mononucleosis, hematological and liver disorders [11] [12].

\section{Case Presentation}

We present a 19-year old, nulliparous woman who presented to the gynecologic outpatient clinic with painless, abdominal distension in the hypogastrium (Figure 1(A)), which developed within few months, and according to the patient was associated with recent menstrual abnormalities. Her medical history was free of any injury, infection or abdominal operation. Ultrasonography demonstrated a large, solitary, thin-walled cystic mass $(16 \times 11$ $\mathrm{cm}$ ) with hypoechoic content and without any diaphragms, filling the entire pelvis (Figure 1(B)). Blood examination for biomarkers (Ca-125, CEA, $\alpha$-FP) and $\beta$-hCG were all negative. The patientgave consent for a robotically-assisted laparoscopic removal of the mass with concurrent preservation of fertility.

Pneumoperitoneum was created with the open laparoscopy technique (Hasson's) at the lower umbilical rim. Laparoscopic examination of the abdomen revealed a large cystic mass within the lower abdomen, with smooth, pale-white wall, resembling an ovarian cyst (Figure 2(A)). Soon enough however, it was realized that the cyst originated from the inferior splenic pole (Figure 2(B)), while other pelvic organs were free of any abnormality.

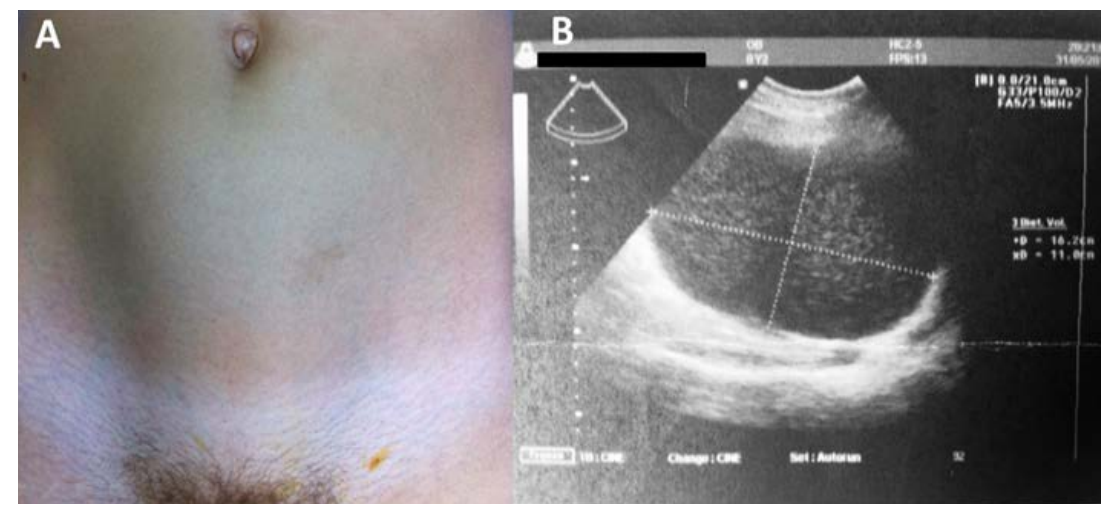

Figure 1. (A) Ventral aspect of the lower abdomen of a 20 year woman with a palpable cystic mass. (B) Ultrasonographic image of lower abdomen. The cyst overfills pelvis. It is smooth, thin walled with no diaphragms and its content is relatively hypoechogenous, resembling an ovarian endometrioma. 


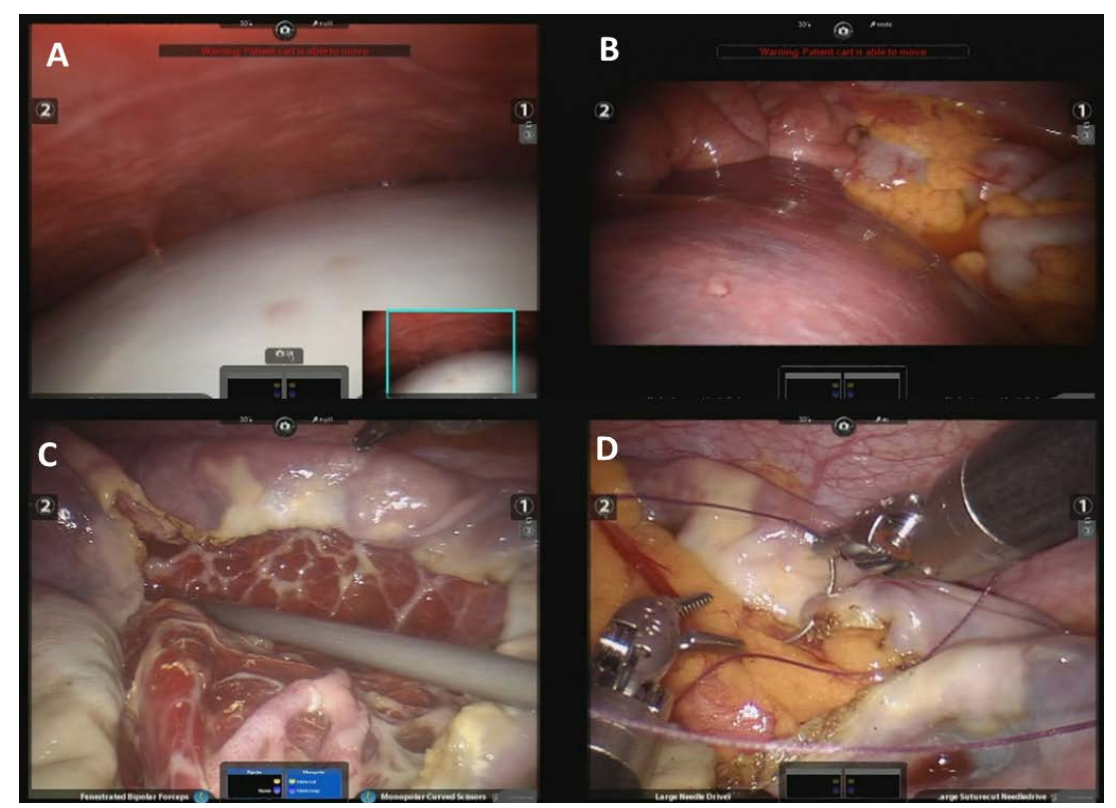

Figure 2. (A) White pale walled cystic mass within the lower abdomen, resembling an ovarian cyst; (B) The spleen lies in orthotopic anatomical position in the left subcostal region. From the lower splenic wall, it extends inferiorly with a thick tonguelike stalk; (C) The cyst has been excised to the edge of the splenic parenchyma. The inner cystic surface is trabecular; (D) Omentopexy. The greater omentum has been mobilized from transverse colon and fixed over the splenic parenchyma with vicryl sutures.

The operation setup was reorganized and repositioned for an upper abdominal operation. The robotic cart was brought against the patient's left shoulder.

The umbilical trocar was the point of entry for the robotic camera. The $5 \mathrm{~mm}$ ancillary trocar on the left flank was converted to $7.0 \mathrm{~mm}$ robotic. A second robotic trocar was introduced in the right hypochondrium (Figure 3). The robotic instruments involved were fenestrated grasper (bipolar) and monopolar scissors.

The cyst was mobilized with care. Adhesions to the mesentery, were excised with monopolar scissors. Bipolar cautery was employed for hemostasis. The cyst was punctured with a $5 \mathrm{~mm}$ needle, and approximately 2 liters of yellow-brown serous fluid were aspirated and sent for cytologic examination and culture. The results later on, were both negative for malignancy and infection, respectively. A specimen of the cystic wall was also sampled for frozen sections which were negative for malignancy (Figure 2(C)). The wall of the cyst was cut along the edge of the splenic tissue, without any injury to the splenic parenchyma. The spleen was preserved intact. In order to prevent recurrence, greater omentum was mobilized from the transverse colon using robotic Harmonic ACE Curved Shears (Intuitive Surgical Inc.) and omentopexy-fixation of the omentum over the splenic cavitywas performed using Vicryl 3 - 0 sutures (Figure 2(D)). Specimen was retrieved in a plain Endobag from the principal trocar incision. A drainage tube was placed and all trocars were removed. Blood loss was minimal, and the operative time was 163 minutes, including docking time. There were no complications in the postoperative course.

During postoperative period, $280 \mathrm{~mL}$ of fluid were collected from the draining tubes and patient was discharged within $72 \mathrm{~h}$. The drainage tube was monitored in a regular outpatient basis, and was removed on the 9th postoperative day. Repeated ultrasonography thereafter showed no intraperitoneal collection.

The patient was followed-up for 16 months after surgery, during which there were no complications or recurrence. Histology reported a non-parasitic splenic pseudocyst with no epithelial capsule.

\section{Discussion}

Treatment of splenic cysts has long been a matter of controversy and in several cases is based upon the experience of surgeon. Additionally, there are only few reports in the literature. Nevertheless, it is generally accepted 


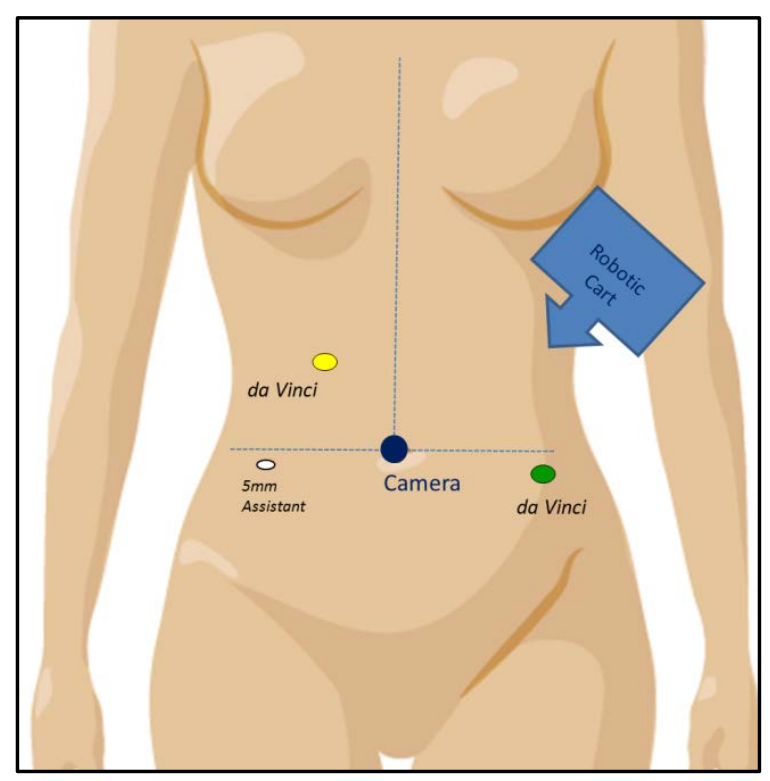

Figure 3. Port placement and docking.

that asymptomatic nonparasitic splenic cysts $<5 \mathrm{~cm}$ in diameter should be managed conservatively with nonoperative measures. If the cyst is larger than $5 \mathrm{~cm}$ or symptomatic, surgical treatment is strongly recommended [13]-[15].

The choice of surgical technique depends on many factors. Patient's body mass index and age, location, size and morphology of the cyst are important factors. In the past, open total splenectomy was the gold standard procedure [4] [15]. Today, however, spleen-preserving operations are preferred due to the fact that asplenic patients are in higher risk of postsplenectomy overwhelming infections and sepsis [16]. These interventions include percutaneous aspiration, marsupialization, fenestration, partial cystectomy, partial splenectomy and cyst decapsulation. Development of laparoscopic and later robotic techniques have largely replaced the conventional open approaches [17].

Percutaneous cyst drainage with or without intracystic injection of alcohol is considered to be an ambiguous therapeutic choice as it is associated with high incidence of recurrence, development of adhesions around the spleen and abscess formation. This procedure, however, can be used preoperatively in order to reduce the size of very large cysts [18] [19].

Marsupialization and fenestration are appropriate for superficially located cysts although high recurrence rates have been shown with fenestration alone. With laparoscopy, these procedures can be performed safely, fast and provide all benefits of minimally invasive surgery. Coagulation, novel suturing devices and recently described "needlescopic" techniques may add benefit to existing marsupialization techniques. At the same time, laparoscopic ultrasound determines the characteristics of the cyst enabling surgeon to choose the suitable part of the cystic wall to be resected [13] [20] [21]. Regarding massively enlarged splenic cysts ( $>15 \mathrm{~cm})$, there are only few reports in the literature about successful marsupialization [22]-[24] or fenestration [22] [25]-[27], and these techniques cannot be recommended yet.

Partial cystectomy or total cystectomy with cyst decapsulationare safe procedures, where the cystic wall is partially or totally excised, respectively. An omental patch over the parenchymal cavity is strongly supported as a method which minimizes the risk of recurrence. However further studies areneeded to determine the extent of cystic wall excision [13] [28]. Salky et al. described the first laparoscopic partial cystectomy with no recurrence of the cyst in a 5 year follow-up [29]. Since then, numerous laparoscopic-assisted cystectomies have been carried out successfully. In a report of Chin et al. [30] laparoscopic partial cystectomy (unroofing) was performed in $77.8 \%$ of patients with a $42.9 \%$ recurrence rate, while decapsulation was performed in $22.2 \%$ of patients without recurrence. Average blood loss was $27 \mathrm{~mL}$ for partial and $63 \mathrm{~mL}$ for total cystectomy, while the mean operation time was 88 and 203 minutes, respectively. In another study from Morgenstern [16], 3 of 22 (13.6\%) patients were also managed successfully by cystectomies with no mortality or complications, over a 28 -year- 
period. In a most recent study, Kalogeropoulos G. et al. [31] confirmed the benefits of laparoscopic decapsulation and reported cyst recurrence in only one patient (16.6\%), over a follow-up period of 28 months.

Partial splenectomy is recommended in cases where the cyst is located at the poles of spleen, or when the cystic cavity is deep (higher risk of recurrence). The main advantage of this procedure is that it has better outcome than splenic autotransplantation while it preserves more than $25 \%$ of splenic parenchyma. Despite the fact that an angiography can be helpful, great surgical skills and thorough knowledge of the individual's splenic vascularization are necessary [13] [14] [32]. Partial splenectomy can also be carried out by laparoscopy. Incision of the splenic capsule can be achieved by means of harmonic scalpel (Ethicon Endo-Surgery, Inc. Cincinnati, Ohio. USA), while ultrasonically activated instruments and Argon Beam Coagulator are also recommended for hemostasis [4] [33] [34]. Szczepanik and Meissner [35] successfully performed open partial splenectomies in 9 of 10 patients (in one patient, insufficient arterial supply led to total splenectomy) with nonparasitic splenic cysts. No recurrences or infections were observed in a follow-up period of 26 months, while the size of remnant splenic parenchyma constituted, on average, for $71 \%$ of preoperative spleen size. Morgenstern [16] managed 14 of 22 non-parasitic splenic cysts (NPSCs) with partial splenectomy; follow up scans showed functional splenic remnants and no cyst recurrences. Wu, S.C. et al. [36] performed five successful partial splenectomies with the aid of a Lin clamp. The mean blood loss was of about $68 \mathrm{ml}$ and the average operation time was 75 minutes. There was no recurrence during a median follow-up period of 34 months. In a review of Uranus and Alimoglu [37], 7 patients with NPSCs underwent open hemisplenectomy and 19 patients underwent laparoscopic hemisplenectomy with success. No postoperative mortality was seen.

For many years, open total splenectomy has been the gold standard for treating splenic cysts. Nowadays, this type of surgery is performed only under specific circumstances. These include polycystic cases, huge cysts, hilum-located cyst, intrasplenic cysts, ruptured cysts and uncontrollable intraoperative bleeding during a spleenpreserving minimally invasive operation. In contrast, laparoscopic splenectomy is the modern gold standard technique in daily practice. Ability of splenic tissue for autotransplantation is noteworthy and mayfacilitate decision for splenectomy [4] [13] [38] [39]. Regarding giant splenic cysts, splenectomy is almost always thesole approach and is mostly donelaparoscopically [5] [17] [40]-[45].

Pelvic or hypogastric non parasitic splenic cysts are very rare entities and usually related to wandering spleens. E.V. Ward et al. [46] reported an unusual case of a 25-year-old female who was conservatively managed for her splenic cyst. Ultrasounds demonstrated more than double increase of the cyst (from 5 to $12 \mathrm{~cm}$ ) and CT showed a cyst located in the pelvis, but originating from the lower splenic pole. Successful splenectomy was performed. Postoperative course of the patient was uneventful and she was discharged four days later. A case report fromSinha and Fisher [47] refers to splenoptosis, resulting from a huge splenic cyst $(15 \mathrm{~cm})$ within the pelvis of a child. After cystic content aspiration, marsupialisation and splenopexy in a retro-peritoneal pouch was performed. The child was followed-up for 2 years. In our case, the spleen was located in the correctanatomic position (orthotopic) and the cyst extended inferiorly from the lower splenic pole, through a thick stalk. Because it was reaching as far as deep inside pelvis, it escaped correct diagnosis with pelvic ultrasonography.

Constant evolution in the field of minimal invasive surgery has led to development of robotic-assisted procedures. Da Vinci robotic system offers accurate motion control, stereoscopic vision, greater anatomical precision and ergonomic comfort [48]. Although recent studies demonstrate several robotic total or partial splenectomies in managing cystic lesions of spleen [48]-[51], robotic spleen-preserving cystectomies have not yet been reported.

\section{Conclusions}

Splenic cysts are infrequent findings in everyday medical practice. In most instances they are confined in the left subcostal region, except for cases of massive splenomegaly or ectopic spleens. Generally, surgical procedures are recommended for cysts larger than $5 \mathrm{~cm}$ diameter, and laparoscopy has proven safe and reproducible in the management of such cases.

Extraordinary cases require a multidisciplinary approach for better results. Good collaboration between gynecologic surgeons and general surgeons is essential at all times, especially when dealing with uncertain pelvic masses.

Robotic surgery with the da Vinci System enhances the minimally invasive maneuverability, provided the surgical team is properly trained. Robot-assisted total cystectomy is equally efficient with its laparoscopic coun- 
terparts, combining all advantages of minimally invasive and spleen-preserving surgery.

\section{References}

[1] Martin, J.W. (1958) Congenital Splenic Cysts. The American Journal of Surgery, 96, 302-308. http://dx.doi.org/10.1016/0002-9610(58)90916-4

[2] Sellers, G.J. and Starker, P.M. (1997) Laparoscopic Treatment of a Benign Splenic Cyst. Surgical Endoscopy, 11, 766768. http://dx.doi.org/10.1007/s004649900446

[3] Labruzzo, C., Haritopoulos, K.N., El Tayar, A.R. and Hakim, N.S. (2002) Posttraumatic Cysts of the Spleen: A Case Report. International Surgery, 87, 152-156.

[4] Hansen, M.B. and Moller, A.C. (2004) Splenic Cysts. Surgical Laparoscopy, Endoscopy \& Percutaneous Techniques, 14, 316-322. http://dx.doi.org/10.1097/01.sle.0000148463.24028.0c

[5] Trompetas, V., Panagopoulos, E., Priovolou-Papaevangelou, M. and Ramantanis, G. (2002) Giant Benign True Cyst of the Spleen with High Serum Level of CA 19-9. European Journal of Gastroenterology \& Hepatology, 14, 85-88. http://dx.doi.org/10.1097/00042737-200201000-00015

[6] Macheras, A., Misiakos, E.P., Liakakos, T., Mpistarakis, D., Fotiadis, C. and Karatzas, G. (2005) Non-Parasitic Splenic Cysts: A Report of Three Cases. World Journal of Gastroenterology, 11, 6884-6887.

[7] Till, H. and Schaarschmidt, K. (2004) Partial Laparoscopic Decapsulation of Congenital Splenic Cysts. Surgical Endoscopy, 18, 626-628. http://dx.doi.org/10.1007/s00464-003-9046-4

[8] Robertson, F., Leander, P. and Ekberg, O. (2001) Radiology of the Spleen. European Radiology, 11, 80-95. http://dx.doi.org/10.1007/s003300000528

[9] Siniluoto, T.M., Paivansalo, M.J., Lahde, S.T., Alavaikko, M.J., Lohela, P.K., Typpo, A.B. and Suramo, I.J. (1994) Nonparasitic Splenic Cysts. Ultrasonographic Features and Follow-Up. Acta Radiologica, 35, 447-451.

[10] Nakashima, A., Nakashima, K., Seto, H., Kamei, T., Kakishita, M. and Kitagawa, M. (1994) Primary Splenic Lymphoma Presenting as a Large Cyst. Radiation Medicine, 12, 42-45.

[11] Cowles, R.A. and Yahanda, A.M. (2000) Epidermoid Cyst of the Spleen. The American Journal of Surgery, $180,227$. http://dx.doi.org/10.1016/S0002-9610(00)00446-3

[12] Andrews, M.W. (2000) Ultrasound of the Spleen. World Journal of Surgery, 24, 183-187. http://dx.doi.org/10.1007/s002689910031

[13] Karfis, E.A., Roustanis, E. and Tsimoyiannis, E.C. (2009) Surgical Management of Nonparasitic Splenic Cysts. Journal of the Society of Laparoendoscopic Surgeons, 13, 207-212.

[14] Tagaya, N., Oda, N., Furihata, M., et al. (2002) Experience with Laparoscopic Management of Solitary Symptomatic Splenic Cysts. Surgical Laparoscopy, Endoscopy \& Percutaneous Techniques, 12, 279-282. http://dx.doi.org/10.1097/00129689-200208000-00016

[15] Smith, S.T., Scott, D.J., Burdick, J.S., et al. (2001) Laparoscopic Marsupialization and Hemisplenectomy for Splenic cysts. Journal of Laparoendoscopic \& Advanced Surgical Techniques, 11, $243-249$. http://dx.doi.org/10.1089/109264201750539781

[16] Morgenstern, L. (2002) Nonparasitic Splenic Cysts: Pathogenesis, Classification, and Treatment. Journal of the American College of Surgeons, 194, 306-314. http://dx.doi.org/10.1016/S1072-7515(01)01178-4

[17] Pitiakoudis, M., Zezos, P., Oikonomou, A., Laftsidis, P., Kouklakis, G. and Simopoulos, C. (2011) Total Splenectomy due to an Unexpected "Complication” after Successful Extended Laparoscopic Partial Decapsulation of a Giant Epidermoid Splenic Cyst: A Case Report. Case Reports in Medicine, 318-208.

[18] Balzan, S.M., Riedner, C.E., Santos, L.M., Pazzinatto, M.C. and Fontes, P.R.O. (2001) Posttraumatic Splenic Cysts and Partial Splenectomy: Report of a Case. Surgery Today, 31, 262-265. http://dx.doi.org/10.1007/s005950170183

[19] Matsutani, T., Uchida, E., Yokoyama, T., Matsushita, A., Matsuda, A. and Sasajima, K. (2009) Laparoscopic Unroofing of a Large Pseudocyst of the Spleen: Report of a Case. Journal of Nippon Medical School, 76, 319-322. http://dx.doi.org/10.1272/jnms.76.319

[20] Kaiwa, Y., Kurokawa, Y., Namiki, K., Matsumoto, H. and Satomi, S. (2000) Laparoscopic Partial Splenectomies for True Splenic Cysts. A Report of Two Cases. Surgical Endoscopy, 14, 865.

[21] Liu, K.K., Lee, K.H., Ku, K.W. and Yeung, C.K. (1996) Decapsulation of Symptomatic Splenic Pseudocyst-A Further Use for Laparoscopic Surgery in Children. The European Journal of Surgery, 162, 921-923.

[22] Sierra, R., Brunner, W.C., Murphy, J.T., Dunne, J.B. and Scott, D.J. (2004) Laparoscopic Marsupialization of a Giant Posttraumatic Splenic Cyst. JSLS: Journal of the Society of Laparoendoscopic Surgeons, 8, 384-388.

[23] Dan, D., Bascombe, N., Harnanan, D., Hariharan, S. and Naraynsingh, V. (2010) Laparoscopic Management of a Mas- 
sive Splenic Cyst. Asian Journal of Surgery, 33, 103-106. http://dx.doi.org/10.1016/S1015-9584(10)60018-8

[24] Takata, M., Rader, C. and Kirton, O. (2007) Laparoscopic Marsupialization of a Giant Nonparasitic Splenic Cyst. Minimally Invasive Surgery Series. http://www.hcplive.com/publications/surgical-rounds/2007/2007-05/2007-05_09

[25] Rotas, M., Ossowski, R., Lutchman, G. and Levgur, M. (2007) Pregnancy Complicated with a Giant Splenic Cyst: A Case Report and Review of the Literature. Archives of Gynecology and Obstetrics, 275, 301-305. http://dx.doi.org/10.1007/s00404-006-0229-9

[26] Madhu, B.S., Dinesh, H.N., Shashikumar, H.B., Kumar, V.K.P. and Naveen, S. (2012) Giant Pseudocyst of Spleen-A Rare Case Report. www.jemds.com

[27] Chang, H.M., et al. (2009) Huge Pseudocyst of the Spleen. Journal of Medical Sciences, 29, 269-271.

[28] Mertens, J., Penninckx, F., DeWever, I. and Topal, B. (2007) Long-Term Outcome after Surgical Treatment of Nonparasitic Splenic Cysts. Surgical Endoscopy, 21, 206-208. http://dx.doi.org/10.1007/s00464-005-0039-3

[29] Salky, B., Zimmerman, M., Bauer, J., Gelernt, I. and Kreel, I. (1985) Splenic Cyst—Definitive Treatment by Laparoscopy. Gastrointestinal Endoscopy, 31, 213-215. http://dx.doi.org/10.1016/S0016-5107(85)72049-4

[30] Chin, E.H., Shapiro, R., Hazzan, D., Katz, L.B. and Salky, B. (2007) A Ten-Year Experience with Laparoscopic Treatment of Splenic Cysts. JSLS: Journal of the Society of Laparoendoscopic Surgeons, 11, 20-23.

[31] Kalogeropoulos, G., Gundara, J.S., Samra, J.S. and Hugh, T.J. (2013) Laparoscopic Stapled Excision of Non-Parasitic Splenic Cysts. ANZ Journal of Surgery, Early View. http://dx.doi.org/10.1111/ans.12367

[32] Smith, S.T., Scott, D.J., Burdick, J.S., Rege, R.V. and Jones, D.B. (2001) Laparoscopic Marsupialization and Hemisplenectomy for Splenic Cysts. Journal of Laparoendoscopic \& Advanced Surgical Techniques, 11, 243-249. http://dx.doi.org/10.1089/109264201750539781

[33] Fan, H., Zhang, D., Zhao, X., Pan, F. and Jin, Z.K. (2011) Laparoscopic Partial Splenectomy for Large Splenic Epidermoid Cyst. Chinese Medical Journal (English), 124, 1751-1753.

[34] Hery, G., Becmeur, F., Mefat, L., Kalfa, D., Lutz, P., Lutz, L., et al. (2008) Laparoscopic Partial Splenectomy: Indications and Results of a Multicenter Retrospective Study. Surgical Endoscopy, 22, 45-49. http://dx.doi.org/10.1007/s00464-007-9509-0

[35] Szczepanik, A.B. and Meissner, A.J. (2009) Partial Splenectomy in the Management of Nonparasitic Splenic Cysts. World Journal of Surgery, 33, 852-856. http://dx.doi.org/10.1007/s00268-008-9868-2

[36] Wu, S.C., Wang, C.C. and Yong, C.C. (2007) Partial Splenectomy for Benign Splenic Cysts with the Aid of a Lin Clamp: Technical Note. World Journal of Surgery, 31, 2144-2147. http://dx.doi.org/10.1007/s00268-007-9240-y

[37] Uranues, S. and Alimoglu, O. (2005) Laparoscopic Surgery of the Spleen. Surgical Clinics of North America, 85, 7590. http://dx.doi.org/10.1016/j.suc.2004.09.003

[38] Rosin, D., Brasesco, O. and Rosenthal, R.J. (2001) Laparoscopic Splenectomy: New Techniques and Indications. Der Chirurg, 72, 368-377. http://dx.doi.org/10.1007/s001040051317

[39] Uccheddu, A., Pisanu, A., Cois, A., et al. (2003) Laparoscopic Management of Non-Parasitic Splenic Cysts. Chirurgia Italiana, 55, 55-60.

[40] Kiriakopoulos, A., Tsakayannis, D., Papadopoulos, S. and Linos, D. (2005) Laparoscopic Management of a Ruptured Giant Epidermoid Splenic Cyst. JSLS: Journal of the Society of Laparoendoscopic Surgeons, 9, 349-351.

[41] Sakamoto, Y., Yunotani, S., Edakuni, G., Mori, M., Iyama, A. and Miyazaki, K. (1999) Laparoscopic Splenectomy for a Giant Splenic Epidermoid Cyst: Report of a Case. Surgery Today, 29, 1268-1272. http://dx.doi.org/10.1007/BF02482221

[42] Ma, J.P., Cai, S.R., Wu, K.M., Liao, B. and Zhan, W.H. (2011) Giant Epithelial Splenic Cyst. Chinese Medical Journal (English), 124, 2799-2800.

[43] Shukla, R.M., Mukhopadhyay, M., Mandal, K.C. and Mukhopadhyay, B. (2010) Giant Congenital Infected Splenic Cyst: An Interesting Case Report and Review of the Literature. Indian Journal of Surgery, 72, 260-262. http://dx.doi.org/10.1007/s12262-010-0068-6

[44] Uludag, M., Yetkin, G., Citgez, B., Karakoc, S., Polat, N. and Yener, S. (2009) Giant True Cyst of the Spleen with Elevated Serum Markers, Carbohydrate Antigen 19-9 and Cancer Antigen 125. BMJ Case Reports.

[45] Chiarugi, M., Galatioto, C., Battini, A., Panicucci, S., Lippolis, P. and Seccia, M. (2006) Giant Epidermoid Cyst of the Spleen with Carbohydrate and Cancer Antigen Production Managed Laparoscopically. Annali Italiani di Chirurgia, 77, 443-446.

[46] Ward, E.V., O’brien, J., Conlon, K. and Torreggiani, W.C. (2010) Unusual Long-Term Complications of a Splenic Cyst. JBR-BTR, 93, 7-9.

[47] Sinha, C.K. and Fisher, R. (2006) Splenoptosis Complicated by a Large Splenic Cyst: Case Report and Discussion of 
Combined Management. Pediatric Surgery International, 22, 605-607. http://dx.doi.org/10.1007/s00383-006-1673-0

[48] Lucandri, G., Felicioni, F., Monsellato, I., Alfano, G., Pernazza, G., Pende, V., et al. (2011) Robotic Splenectomy for Mesothelial Cyst: A Case Report. Surgical Laparoscopy, Endoscopy \& Percutaneous Techniques, 21, e93-e96. http://dx.doi.org/10.1097/SLE.0b013e31820b8a7c

[49] Vasilescu, C., Tudor, S., Popa, M., Tiron, A. and Lupescu, I. (2010) Robotic Partial Splenectomy for Hydatid Cyst of the Spleen. Langenbeck's Archives of Surgery, 395, 1169-1174. http://dx.doi.org/10.1007/s00423-010-0647-9

[50] Fedorov, A.V., Kriger, A.G., Berelavichus, S.V., Efanov, M.G. and Gorin, D.S. (2010) [Robotic-Assisted Abdominal Surgery]. Khirurgiia (Mosk), 16-21.

[51] Tomulescu, V., Stănciulea, O., Bălescu, I., Vasile, S., Tudor, S., Gheorghe, C., et al. (2009) First Year Experience of Robotic-Assisted Laparoscopic Surgery with 153 Cases in a General Surgery Department: Indications, Technique and Results. Chirurgia (Bucur), 104, 141-150. 
Scientific Research Publishing (SCIRP) is one of the largest Open Access journal publishers. It is currently publishing more than 200 open access, online, peer-reviewed journals covering a wide range of academic disciplines. SCIRP serves the worldwide academic communities and contributes to the progress and application of science with its publication.

Other selected journals from SCIRP are listed as below. Submit your manuscript to us via either submit@scirp.org or Online Submission Portal.
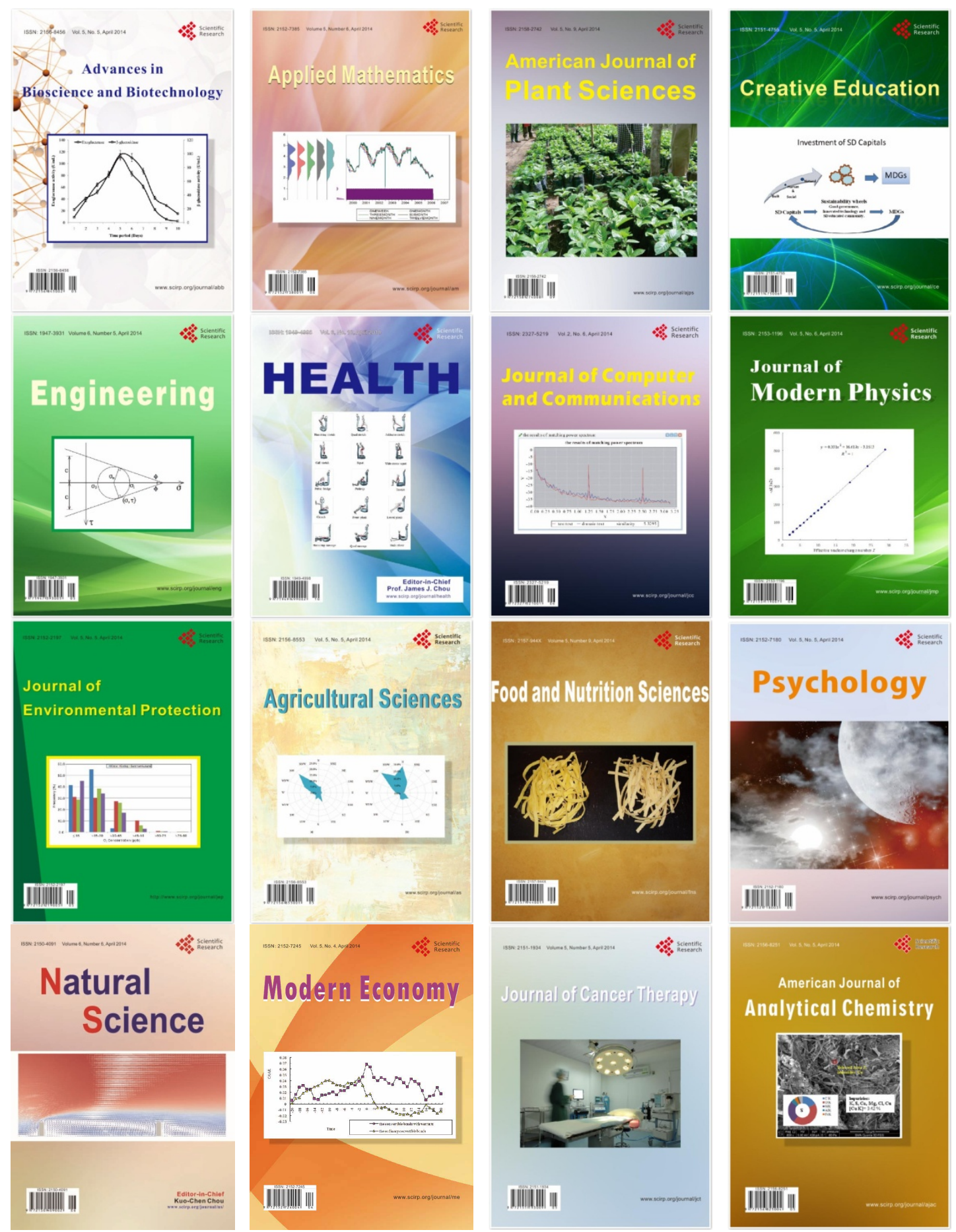